\title{
ARTIGO
}

\section{Metodologias para gestão da informação}

\author{
Methodologies for information management
}

Edmeire Cristina PEREIRA ${ }^{1}$

RE S U M O

Este artigo aborda a criação, adaptação e/ou utilização de metodologias voltadas aos processos de gestão da informação, como base para a prática profissional e a investigação científica. Visa relacionar e descrever algumas das principais metodologias para o mapeamento de fluxos informacionais, tais como a metodologia do INFOMAP de Burk e Horton e a Norma AFNOR $\mathrm{XP} \times$ 50-053. Estas e outras metodologias relacionadas neste artigo, serão úteis para os gestores de informação nas atividades administrativas das suas Unidades.

Palavras-chave: metodologias para gestão da informação, técnicas de gestão, metodologia do INFOMAP, gerência de recursos informacionais, norma AFNOR XP X 50-053.

\section{A B S T R A C T}

This paper discusses the creation, adaptation and/or utilization of methodologies intended for the information management processes, as a basis for professional practice and scientific investigation. It aims to report and describe some of the main methodologies for charting the informational flow, such as the INFOMAP Methodology by Burk and Horton and the AFNOR Norm XP X 50-053. These and other methodologies analyzed in this article would be of use to information managers in the administrative activities of their Units.

Key words: methodologies for information management, management techniques, INFOMAP methodology, information resources management, AFNOR norm XP X 50-053.

\footnotetext{
${ }^{1}$ Mestre em Biblioteconomia e Ciência da Informação, Professora Assistente I do Departamento de Ciência e Gestão da Informação (DECIGI), Universidade Federal do Paraná. Av. Prefeito Lothário Meissner, 3400, Jardim Botânico, Campus III, 80210-170, Curitiba, PR, Brasil. E-mail: edmeirepereira@pop.com.br Recebido em 29/4/2003 e aceito para publicação em 20/1/2004.
} 


\section{N T R O D U Ç Ã O}

Este artigo analisa alguns métodos/metodologias, técnicas e ferramentas da Gestão da Informação, para situar os profissionais da informação no "como orientar" a gestão de processos e serviços informacionais, com mais eficiência e eficácia. Visa fornecer um suporte teórico para a compreensão do funcionamento dessas metodologias e para o entendimento da dinâmica dos fluxos de informação na sociedade contemporânea.

$\mathrm{Na}$ visão de Passos (1999), estamos vivendo a Terceira Revolução Industrial e esta tem como características: a) o desenvolvimento de um conjunto de inovações tecnológicas de largo espectro na utilização e, mutuamente estimuladoras entre si, nas áreas de novos materiais, biotecnologia e, sobretudo, na microeletrônica; b) formas de gestão inovadoras que vêm sendo implementadas de modo a superar a antiga organização por postos de trabalho fixos com tarefas ultra-especializadas, resultantes das análises de tempo de movimento "taylorizadas"; c) uma revolução nos processos produtivos, designada como automação flexível, vai superando a antiga automação rígida das cadeias fordistas de produção; d) uma profunda modificação por processos organizacionais, nas estratégias e na cultura das organizações empresariais.

Portanto, a combinação de: inovações tecnológicas, formas de gestão inovadoras, revolução nos processos organizacionais, está modificando radicalmente as estratégias corporativas, a cultura e a ética dessas organizações empresariais. Como conseqüência desse fato histórico e social, as Unidades de Informação também são forçadas a rever seus processos gerenciais e produtivos. Não podem mais trabalhar pela lógica da Sociedade Industrial, porque a atualidade já está imersa na Sociedade Informacional, a qual tem por características marcantes: "a verdadeira polivalência, que chamamos de polifuncionalidade, para distin- güi-la da polivalência tapa-buracos da mecanização; a flexibilidade (a variedade dos usos possíveis das máquinas informacionais); e a estrutura em redes descentralizadas" (LOJKINE, 1999, p.73).

Com a economia de serviços em ascensão e baseada no insumo informação e, a predominância de profissões técnicas com a formação de "n" especialistas, tal é o caso da Gestão da Informação, vê-se, com efeito, o quanto é importante o desenvolvimento e a construção e avaliação de metodologias aplicáveis aos diferentes tipos de organização e em diferentes funções informacionais. A Gestão da Informação pode se dar em três situações: a) como teoria: um conjunto de saberes interdisciplinares das áreas de "Administração de Empresas, Ciências da Informação e Tecnologias de Informação", que culmina numa "formação discursiva" complexa; b) como prática: um conjunto de métodos/metodologias, técnicas e ferramentas voltado para a coleta, processamento, difusão e uso das informações pelas organizações, com o intuito de transformar dados em informações de "relevância e propósito", que sirvam à tomada de decisões de quem delas precise; c) como processo: um recurso estratégico de intervenções governamentais não só nos universos da Ciência e Tecnologia, como também, no universo econômico das nações, que necessitam da informação para a transferência de conhecimentos entre indivíduos, organizações ou mesmo, países, para aumentar a sua competitividade global (PEREIRA, 2001).

Embora seja reconhecida sua importância, pouco ainda se estuda e se utiliza (pelo menos, no Brasil) de metodologias para Gestão da Informação junto às indústrias, no comércio e nos serviços. O grupo de pesquisa da Profa. Dra. Patrícia Z. Marchiori da Universidade Federal do Paraná (UFPR), denominado Metodologias para Gestão da Informação, criado em 2002, é um exemplo salutar desse esforço da área em 
fazer pesquisas a respeito do tema em questão. As repercussões dos trabalhos do grupo da Dra. Marchiori podem ser vistas no Diretório dos Grupos de Pesquisa no Brasil, editado pelo Conselho Nacional de Desenvolvimento Científico e Tecnológico (CNPq).

Verifica-se, portanto, a necessidade de investigar não só a informação que está presente nas organizações, mas também, como são utilizados e gerenciados os recursos informacionais e o apoio das tecnologias de informação às suas atividades. Nesse sentido, é dada ênfase à abordagem de processo estratégico à tomada de decisões, como forma de identificar as atividades de geração, fluxo, disseminação e uso da informação.

\section{M ÉTODOS E TÉCN ICAS}

A maneira de pôr uma estratégia em funcionamento difere muito de empresa para empresa. Assim, daremos ênfase não a um método em especial, mas a alguns métodos, técnicas e ferramentas que os gestores podem usar em suas atividades. Começaremos por Bryson (1992), Tarapanoff (1995) e Davenport \& Prusak (1998a).

Para Bryson (1992), quaisquer que sejam os rótulos dos administradores (ou gestores) de bibliotecas ou centros de informação, estes deverão primar por um perfil sempre mais inovador e empreendedor. E, para que isto ocorra, faz-se mister o emprego de técnicas de gestão. $O$ autor elegeu em sua obra, um estudo global da estratégia de gestão, a partir do trabalho de Kast e Rosenzweig (1984). Estes autores dividiram um entorno interno de uma biblioteca ou de um centro de informação em cinco subsistemas, a saber: subsistema de gestão; de estrutura; de técnica; psicossocial e de objetivos e valores.

Para Bryson (1992), a utilidade desse método está em que o gestor pode mover-se sistematicamente através dos problemas de gestão que afetam o entorno interno das bibliotecas ou centros de informação. Também, pode analisar cada um dos cinco subsistemas tomando nota de como influem sobre cada um dos demais e analisar as áreas que requerem sua atenção. Como Bryson (1992) não faz distinção aparente, em seu livro, dos termos: técnica, método e ferramentas, ele nos diz que "tradicionalmente tem-se considerado que os gestores usam três métodos para levar a cabo suas tarefas: o técnico, o de relações humanas e o conceitual". A estes, também podem-se acrescentar: os métodos de diagnósticos e de análise.

Sintetizamos assim, esses métodos descritos por Bryson (1992):

1. Métodos Técnicos: são compreendidos como os métodos dos quais se necessitam para levar a cabo uma tarefa. Incluem-se, nestes métodos, por ex., o conhecimento e a experiência técnica necessários para usar sistemas de informação em linha, bibliografias nacionais e comerciais, terminais de computador, reprodutores de videodisco ou um conhecimento dos distintos esquemas de classificação bibliográfica. Enfim, são métodos mais usados pelos gestores de primeira linha ${ }^{2}$, que precisam treinar e supervisionar subordinados.

2. Métodos de Relações Humanas: diz-se dos métodos que utilizam-se dos gestores para manter sua rede de contatos pessoais interna

\footnotetext{
2 Bryson (1992) diz que os gestores atuam em diferentes níveis em uma instituição e hierarquia. Assim, segundo ele, em geral, se diz que há gestores: de al to nível, nível médio e primeira linha. Os de alto nível, detêm o controle global da instituição e de seus objetivos, que deve alcançar seus subordinados. Os de nível médio, são intermediários entre a alta direção e os gestores de primeira linha: eles recebem as estratégias e políticas gerais da alta direção e as transformam em programas específicos, que vão ser postos em ação, pel os gestores de primeira linha. Estes, por sua vez, são encarregados da administração cotidiana dos recursos para al cançar os objetivos a curto prazo.
} 
ou externamente à sua organização. São os chamados métodos interpessoais.

3. Métodos Conceituais: podem definir-se como a capacidade para compreender a relação das partes com o todo e o todo dissociando-se em partes. Também requerem uma compreensão da relação entre causa e efeito dentro e fora da organização. São utilizados pela alta direção e nível intermediário.

4. Métodos de Diagnóstico: estes métodos proporcionam a capacidade para adquirir, analisar e interpretar a informação, para determinar a causa das mudanças nos processos de entrada, saída ou de transformação da informação. Por ex.: um aumento no ritmo de ingressos de publicações na biblioteca é o resultado de uma mudança na política de seleção de livros.

5. Métodos Analíticos: enquanto os métodos de diagnóstico permitem aos gestores compreender uma situação, os analíticos permitem-Ihes determinar a ação apropriada. Os métodos analíticos permitem que o bibliotecário ou o profissional da informação determinem a causa da mudança e, ou bem apliquem uma ação corretiva ou bem tirem vantagem da situação. Complementam os métodos de diagnóstico.

Além desses métodos, Bryson (1992, p.28) define que: "uma técnica pode descrever-se como a capacidade de traduzir um conhecimento em uma ação que finaliza em um resultado desejado".

Para Tarapanoff (1995), os conceitos de métodos e técnicas apresentados em seu livro, são produtos de pesquisa utilizados na prospecção estratégica e no acompanhamento administrativo de sistemas de informação, dentro da linha de pesquisa contínua da autora no âmbito do tema "Macroplanejamento e Planejamento Estratégico para Sistemas de Informação".
Essas técnicas de prospecção e acompanhamento (Figura 1) inserem-se em abordagens teóricas de caráter sistêmico e dentro de métodos consagrados de levantamento: experimental, descritivo, histórico e outros (TARAPANOFF, 1995). Oferecem uma visão geral de técnicas que podem ser utilizadas na prospecção e no acompanhamento administrativo, subsidiando a formação do Sistema de Informações Gerenciais e auxiliando no estabelecimento de padrões ou indicadores de desempenho organizacional (TARAPANOFF, 1995). O trabalho enumera, talvez, as técnicas mais úteis para os processos de administração de sistemas informacionais (TARAPANOFF, 1995).

Junto ao Glossário de Termos Técnicos, do livro de Tarapanoff (1995), encontramos:

Métodos: estudo de procedimentos. Direcionamento das etapas fundamentais de qualquer processo.

Técnica: conjunto de procedimentos e recursos aplicados a um objeto específico, dentro do(s) métodos(s) adotado(s).

Chamou-nos atenção três técnicas, que no referido Glossário, são definidas como "métodos", a saber:

Delfos $^{3}$ : método de exploração e determinação de probabilidades de ocorrência de eventos futuros.

Monitoramento Tecnológico: método de acompanhamento e vigilância constantes, centrado nos aspectos tecnológicos e científicos, que visam monitorar as oportunidades e ameaças das organizações.

Pesquisa Histórica: método que busca a reconstrução de fatos passados através da atividade de levantamento de dados retrospectivos sobre determinado assunto ou episódio.

\footnotetext{
3 Para a Técnica Delphi, ver: GUPTA, U.G.; CLARKE, R.E. Theory and applications of the Delphi technique: a bibliography (1975-94). Technological Forecastig and Social Change, v.53, n.2, p.185-211, 1996.
} 


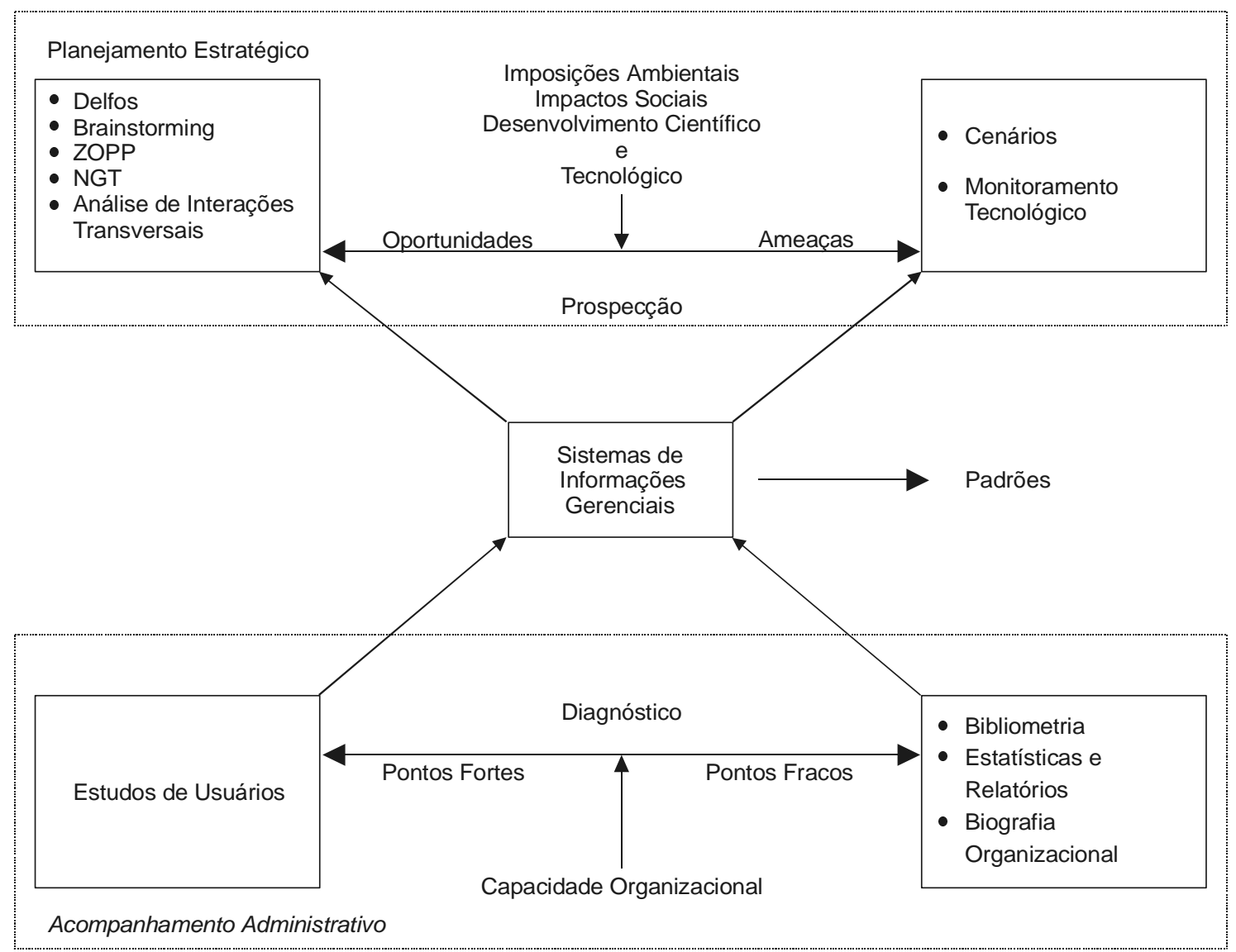

Fonte: Tarapanoff (1995, p.20).

Figura 1. Sistema de Informação Estratégico/Administrativo (desenvolvido a partir do "Modelo Conceitual" de Svidén, 1988, p.163).

Outro termo que chamou-nos a atenção foi: Estudos de Usuários, que no corpo da obra é elencado como uma das técnicas de acompanhamento administrativo. Porém, sua definição por Pinheiro (1982, p.108), é assim:

"Estudos de Usuários: Método de sondagem objetiva, centrado no usuário, que encerra várias técnicas de coleta de dados, caracterizando-se, desta maneira, como um método multidisciplinar. Abrange o estudo das "necessidades de informação" e os "usos da informação" por grupos de indivíduos”.

No entanto, no referido Glossário (TARAPANOFF, 1995, p.120), encontramos:
"Estudos de Usuários: Técnica utilizada para traçar o perfil de usuários de um determinado produto, serviço ou centro de documentação e a partir daí direcionar e padronizar o atendimento, melhorar a qualidade dos produtos oferecidos e atender da melhor maneira possível a demanda e a necessidade dos usuários".

Outros métodos e técnicas aparecem na literatura, como os de análise global (levantamento de dados, fluxograma, diagnósticos de problemas, folha de verificação, gráficos de Pareto, diagramas de causa e efeito), de geração de idéias ISN (matriz decisória, de Kepner \& Tregoe (GUT), técnica de Fire, e de implementa- 
ção (Pert, análise de problema potencial) (TARAPANOFF, 1995).

Davenport e Prusak (1998a), acreditam que algumas técnicas tradicionais podem ajudar a desenvolver métodos ou iniciativas específicos. Isso inclui a análise dos negócios ou de um setor, uma abordagem funcional ou "de processo de adição de valor" e benchmarking.

- Análise de Negócios e de Setor: uma análise estratégica fundamental pode identificar o tipo de informação que deve receber ênfase: a posição básica da empresa no mercado; concorrentes tradicionais e alternativos; forças externas que impulsionam a demanda de mercado; estrutura e função da organização; mudanças que a empresa precisa sofrer para obter êxito em sua atividade.

- Verificando a Escala de Valores: quando uma empresa enfatiza certas funções dentro da cadeia de valor isto é, como as várias funções agregam valor a seus produtos e serviços como parte da estratégica de negócios, existem implicações correspondentes na estratégia informacional. Se a estratégia da cadeia de valor destaca a distribuição e as relações de parceria com varejistas, por exemplo, então a estratégia informacional deve centrar-se em produtos e transporte. Mais: deve ser coordenada com a estratégia de seus principais varejistas.

- Benchmarking: embora o gerenciamento de dados, geralmente, não contenha as avaliações quantificáveis necessárias à realização do benchmarking, existem algumas exceções. Além de fornecer acesso à informação, muitas empresas começam a oferecer análises e interpretações úteis das informações. A Bloomberg, fornecedora de dados financeiros e empresariais, por exemplo, iniciou suas operações oferecendo não apenas dados sobre os preços das ações, mas também explicações textuais de por que eles se alteram o que levou ao estabelecimento bem-sucedido de um serviço de notícias financeiras.

Pelas conceituações acima, percebemos quão ambíguas elas são. Ora um método é chamado de técnica, ora uma técnica é chamada de método. Em nosso entendimento, corroboramos com Dencker (1999, p.23), que se refere ao método como uma "orientação geral para se chegar a um fim determinado" e entende que "a forma de aplicação do método é a técnica". Ou seja, o método estabelece o que fazer e a técnica é o como fazer. Portanto, esses dois procedimentos, se bem combinados, garantem a confiabilidade dos resultados pelos pesquisadores e/ou gestores de sistemas de informação.

\section{Metodologia}

Podemos utilizar vários métodos para adquirir conhecimento. A maneira como fazemos isso é a metodologia.

A disciplina de metodologia científica estuda os métodos e processos utilizados para a obtenção e o desenvolvimento do conhecimento científico. Ela estuda, portanto, como se faz ciência.

Para Dencker (1999), metodologia: a) é a maneira concreta como se realiza a busca de conhecimento; b) o que fazemos para adquirir o conhecimento desejado de maneira racional e eficiente.

Em termos organizacionais, uma metodologia já bastante conhecida internacionalmente é a metodologia do INFOMAP ${ }^{4}$, de Burk e Horton (1988). Sua importância reside no fato de servir à identificação dos recursos informacionais (fontes, serviços e sistemas) nas organizações. Esses autores ficaram conhecidos como os criadores do conceito de mapeamento da informação, ao incluir em seus mapas as fontes, os serviços e os sistemas. A figura 2, do livro

4 Sobre este assunto, ver Ponjuán Dante (1998), capítulo 3. 
Ecologia da Informação, de Davenport e Prusak (1998), mostra uma versão simplificada dessas categorias. Ela ilustra que o termo 'mapa' não precisa ser entendido em sentido literal. A idéia é fornecer ao usuário algumas pistas sobre o paradeiro das informações. Se o quadro fontes, serviços e sistemas for aplicável na localização, não tem de incluir coordenadas geográficas (Quadro 1).

Burk e Horton (1988) ao editarem o livro Infomap: a Complete Guide to Discovering Corporate Information Resources, que tornou-se um clássico em Gerência de Recursos Informacionais (GRI), levantaram o conceito de Entidade de Recursos de Informação (ERI).

Ponjuán Dante (1998), assim o explicita: "quando se trata de energia elétrica, usamos watts. Quando se trata de recursos financeiros, usamos a moeda do país. E quando nos deparamos com o tratamento da informação como recurso, então, usamos os conceitos de entidade de recursos de informação".

Afinal, o que é ERI? Trata-se de uma "configuração de pessoas, tecnologias e informações que têm a capacidade de gerar, adquirir, fornecer, processar, armazenar e disseminar informações" (PONTES, 1999).

Esse processo consiste em inventariar todas as informações que supostamente constituem um recurso, que tenham sido geradas internamente ou sejam produzidas externamente; sejam manuais ou em suportes eletrônicos; sejam fontes, serviços ou sistemas.
Para essas três categorias (fontes, serviços e sistemas), Burk e Horton (1988), as definem assim:

Fontes: são os "estoques de conhecimento" mantidos ou acessados (interna ou externamente) à organização.

Serviços: são atividades necessárias na aquisição, processamento ou transmissão de dados ou informações ou em prover produtos informacionais.

Sistemas: séries de processos estruturados e integrados para 0 manuseio da informação ou caracterização de dados pelo processamento de inputs sistemáticos e repetitivos, atualizações de arquivos e outputs. Por ex.: sistemas de dados financeiros, bibliográficos ou científicos, podendo ser manual ou automático.

Essa metodologia do INFOMAP se desenvolve em quatro etapas, a saber: confecção do inventário preliminar, determinação dos custos e agregação de valores; preparação das técnicas de mapeamento da informação e, identificação dos recursos da organização.

Quanto aos conceitos de GRI, serão tratados no próximo bloco.

Quadro 1. Recursos Instalados em Relação a Usuários, Fornecedores e Gerentes.

\begin{tabular}{|c|c|c|c|c|c|}
\hline \multirow{3}{*}{$\begin{array}{l}\text { Tipos } \\
\text { de Recursos } \\
\text { de Informação }\end{array}$} & \multirow{3}{*}{$\begin{array}{r}\begin{array}{r}\text { Unidades } \\
\text { Organizacionais }\end{array} \\
\end{array}$} & \multicolumn{4}{|c|}{ Organização } \\
\hline & & \multicolumn{4}{|c|}{ FilialX } \\
\hline & & Unidade $\mathrm{A}$ & Unidade B & Unidade C & Unidade D \\
\hline & Fontes & & & & \\
\hline & Serviços & & & & \\
\hline & Sistemas & & & & \\
\hline
\end{tabular}

Fonte: Davenport e Prusak (1998b, p.211, Figura 2. Mapa de Tipos de Recursos Informacionais.). 


\section{GERÊ NCIA DE RECURSOS I N F O R M A C IO N A IS (GRI)}

Information Resources Management (IRM) é termo do Inglês, que foi traduzido para o idioma Português como: Gerência de Recursos Informacionais (GRI) (RODAS, 1995).

Trata-se de um conceito "chave" para a área da Ciência da Informação, desde meados da década de 80, porque foi, por essa época, que as Tecnologias de Informação passaram a fazer parte indissociável da área e, também, porque os países desenvolvidos começaram a incluir, em sua pauta política, o conceito de "informação estratégica", principalmente, na economia, que começava a se globalizar cada vez mais.

O Relatório do Grupo Inteligência Econômica e Estratégia das Empresa, presidido por Henri Martre a serviço do Comissariado Geral do Plano, do Governo Francês, publicado em 1994, é um exemplo mundial disso, ou seja, dessa preocupação com a competitividade internacional. Passos (1999), em seu artigo sobre Novos Modelos de Gestão e Informações, cita vários trechos desse Relatório, do qual salientamos: "Por conseqüência, a gestão estratégica da informação econômica torna-se uma ferramen-ta integral para a compreensão permanente da realidade dos mercados, das técnicas e dos modos de pensar dos concorrentes, de sua cultura, de suas intenções e de suas capacidades de executá-las. Essa atividade situa-se no âmago dos sistemas nacionais de inteligência econômica, que se tornam, a partir desse momento, as alavancas (ou os instrumentos) essenciais a serviço da competição e do emprego.

Com efeito, não foi só a área econômica dos países que foi privilegiada com essa nova mentalidade de gestão estratégica pela informação. As organizações, talvez, tenham sido as maiores beneficiadas. E num nível mais particular, as unidades de informação corporativas ou empresariais, que tiveram de se adaptar às mudanças sócio-políticas; econômico-culturais e, principalmente, tecnológicas.

Para Burk e Horton citados por Ponjuán Dante (1998 p. 136).

GESTIÓN DE RECURSOS DE INFORMACIÓN: Es el proceso dentro del seguimiento de la gestión de información que sirve al interés corporativo. La GRI persigue asociar la información para beneficio de la organización en su totalidad mediante la explotación, desarrollo y optimización de los recursos de información. Los intereses de la organización generalmente se manifiestan en las metas $y$ objetivos corporativos. Por tanto, la gestión de recursos de información es el vínculo gerencial que conecta los recursos de información corporativos con las metas y objetivos de la organización.

E para LONGO e FRESNEDA, 1999). GERÊNCIA DE RECURSOS INFORMACIONAIS: É a maneira eficaz de tratar integralmente a informação interna e externa, para uso estratégico por tomadores de decisão nas organizações, visando otimizar a performance dessas instituições e sintonizá-las com o ambiente externo

No Brasil, as escolas superiores com mestrado e/ou doutorado em Ciência da Informação também se apressaram em estruturar os seus cursos de Pós-Graduação, com áreas de concentração em Sistemas de Informação. É o caso da Pontifícia Universidade Católica de Campinas (PUC-Campinas), com o seu Mestrado em Biblioteconomia e Ciência da Informação, cuja área de concentração é em "Planejamento e Administração de Sistemas de Informação" e, a 
Universidade Nacional de Brasília (UnB) com seu Mestrado em Ciência da Informação e cuja área de concentração é "Planejamento, Organização e Administração de Sistemas de Informação". Também, a Universidade Federal de Minas Gerais (UFMG) tem seu Mestrado em Ciência da Informação (FUNDAÇÃO..., 1998).

Dessa última Escola, a da UFMG, encontramos no antigo periódico da própria instituição - Revista da Escola de Biblioteconomia da UFMG, referente ao ano 1990, três artigos que versam sobre GRI, a saber: Blaise Cronin (1990) e seu Esquemas conceituais e estratégicos para a gerência da informação; Anna da Soledad Vieira (1990) e Demanda por gerentes de recursos informacionais: um estudo preliminar ; e João Batista Pereira et al. (1990) com seu texto: Cenários para a gerência de recursos informacionais no Brasil. Respectivamente, estes textos abordam: 1) a evolução e conceitos da área de GRI; 2) indicadores básicos de pesquisa de mercado, realizada entre dezembro de 1988 e abril de 1989, visando à criação do curso de especialização em GRI, na UFMG; 3) apresenta cenários otimista, pessimista e mais provável às perspectivas futuras da GRI no Brasil.

Outro trabalho interessante encontrado na literatura é o de Cianconi ${ }^{5}$ (1991), que ao discorrer sobre as mudanças nos perfis profissionais, acredita que:

"Encarar a informação em todo o seu complexo contexto é a base da filosofia da Administração dos Recursos de Informação (ARI), que consiste na visão integrada de todos os recursos envolvidos no ciclo da informação (geração, coleta, organização, armazenamento, disseminação e uso sejam a informação propriamente dita (conteúdo), os recursos tecnológicos e os recursos humanos".
Para os autores Megginson et al. (1998), a administração da informação é especialmente importante no controle, porque os administradores não podem realizar algo sem informação adequada e pertinente do que foi planejado e do que aconteceu com os planos. Para essa informação ser útil, ela deve ser: 1) pertinente em relação a algum aspecto da tarefa do administrador; 2) vir na ocasião oportuna, pois informação atrasada não tem valor; 3) precisa, pois decisões baseadas em informações imprecisas podem causar mais dano do que a falta de informação; 4) relevante. Por exemplo, gerentes de operação precisam de informações sobre custos e produtividade; gerentes de marketing precisam de informações sobre projeção de vendas e índices de propaganda; e gerentes de recursos humanos precisam de informações sobre rotatividade de pessoal, necessidade de contratação, salários e benefícios. Ver por exemplo, o caso de sucesso da Dillard's.

\section{FER R A M E N TA S}

Gestores de Informação têm de estar constantemente atentos à utilização de métodos, metodologias, técnicas e ferramentas modernos, para gerenciar suas atividades, tendo como objetivo facilitar a geração de informações oportunas para a tomada de decisão. E em projetos e atividades de melhoria da qualidade, a tomada de decisão dar-se-á a partir de análises de dados e situações.

Antes de exemplificarmos esta parte, encontramos duas definições para ferramenta: a) "Qualquer instrumento ou utensílio" (MINIDICIONÁRIO..., 1992, p.228); b) "Métodos e dispositivos de acessórios que auxiliam a execução de tarefas e atividades visando melhores níveis de qualidade e produtividade" (GESTÃO, 1997, p.134).

5 Ver também: CIAN CONI, R.B. G estão da Informação na sociedade do conhecimento. Brasília, DF: Senai/DN, 1999. 120p. 
Enfim, a ferramenta, metaforicamente, "é o moinho que processa o trigo" (SANTOS, 2001).

Em termos organizacionais, ferramentas são controles de toda ordem, as estimativas, os mapas de controle de materiais, as planilhas, os softwares de bancos de dados.

Ponjuán Dante (1998), classifica as ferramentas e técnicas em duas modalidades: ferramentas para dados numé-ricos; ferramentas para dados não-numéricos. Os Quadros 2 e 3 exemplificam esta diferenciação.

Finalizamos esta parte com as considerações de Santos (2000, p.205) sobre métodos e ferramentas para a Gestão da Inteligência Competitiva. Este autor, salienta que "o tomador de decisão necessita de informações relevantes, mas, antes de tudo, precisa de dispositivos de

Quadro 2. Ferramentas e Técnicas para Dados Não-Numéricos.

\begin{tabular}{ll}
\hline Ferramentas e Técnicas & Utiliza-se para \\
\hline Diagrama de afinidade & $\begin{array}{l}\text { - Agrupar um número grande de idéias, opiniões ou aspectos sobre um } \\
\text { tópico. }\end{array}$ \\
Benchmarking & Comparar um processo aqueles dos líderes reconhecidos e identificar \\
& oportnidades para o melhoramento da qualidade. \\
Brainstorming & - Identificar possíveis soluções a problemas e oportunidades potenciais \\
& para o melhoramento da qualidade. \\
Diagrama de causa-efeito & - Analisar relações de causa-efeito e facilitar a solução de problemas a \\
& partir dos sintomas que conduzem as causas e facilitam a identificação \\
de soluções. & Descrever um processo existente ou para desenhar um novo processo. \\
Diagrama de fluxos & Mostrar as relações entre um tópico e seus elementos componentes. \\
\hline
\end{tabular}

Fonte: Ponjuán Dante (1998, p.99).

Quadro 3. Ferramentas e Técnicas para Dados Numéricos.

\begin{tabular}{ll}
\hline Ferramentas e Técnicas & Utiliza-se para \\
\hline Gráfico de controle & - Avaliar a estabilidade dos processos; determinar quando um processo \\
& requer ou não ajustes e para confirmar o melhoramento de um \\
& processo. \\
- & Representar o padrão de variação de dados. \\
Histograma & Representar em ordem de importância, a contribuição de cada \\
Diagrama de Pareto & aspecto ao efeito total; ordenar em um... as oportunidades de \\
& melhoramento. \\
- Identificar e confirmar relações entre dois conjuntos de dados & associados; confirmar relações antecipadas entre dois conjuntos \\
Diagrama de dispersão & associados de dados.
\end{tabular}

Fonte: Ponjuán Dante (1998, p.100) 
filtros, pois está exposto a uma massa infinita de informações irrelevantes, muitas delas, que ele mesmo solicitará. As técnicas, os métodos e as ferramentas desenvolvidos para o processo de inteligência competitiva são concebidos segundo o paradigma de sistemas de informação estratégica dirigido para o receptor".

Para esse enfoque, a filtragem (análise e/ou avaliação) e a condensação (síntese/rentabilização) são consideradas as duas principais funções de um Sistema de Gestão de Informações Estratégicas (SGIE). Assim, na visão do autor, para que a gestão da informação seja otimizada nas empresas, além das ações de construção de bancos de dados, de sistemas de codificação, de indexação de arquivos, linguagem de acesso, os tomadores de decisões deverão reunir aptidões para:

a) selecionar, avaliar, formalizar e validar a informação;

b) estabelecer regras e práticas comuns;

c) estabelecer referências, implantar ferramentas que democratizem a informação;

d) assegurar-se de que as referências estão sendo compartilhadas por quem de direito;

e) criar ferramentas de orientação, de links entre os diferentes documentos;

f) definir regras de circulação e de prioridades de acesso à informação (SANTOS, 2000, p.206).

Dessa forma, o que vem a ser, então, a Inteligência Competitiva (IC)?

O autor recorre a Martinet e Mart (1995) citados por Santos (2000, p.207), quando afirmam:

Esse conjunto de processos e habilidades está conformado, no mundo globalizado, dentro de um sistema de ações estruturadas, cuja terminologia que o identifica e, está sendo adotada pela comunidade científica da área de Ciência da Informação, em nível internacional, é a de Inteligência Competitiva.

Para Fuld citado por Santos (2000, p.207), no universo da organização, a inteligência é entendida como "proposições que lhe permitem tomar decisões." E as companhias que conseguem converter informações em inteligência são as que ganham a competição. Quanto aos Sistemas de Inteligência Competitiva, dentro da organização, Fuld acredita que os mesmos, não implicam em resmas impressas de bases de dados, nem na redação de relatórios volumosos e densos ou, muito menos, de ações de espionagem, roubo ou grampo telefônico. Seu significado, nesse contexto é, basicamente, a informação útil aos tomadores de decisão das empresas.

Porém, como otimizar informações úteis e críticas? Santos (2000, p.208) comenta que uma iniciativa pioneira partiu da França, em abril de 1998, com a edição e divulgação da Norma XP X 50-053, da Association Française de Normalisation (AFNOR). Essa norma, que tem por título: Prestations de veille et prestations de mise en place d'un systeme de Ville, aplica-se, essencialmente, à prestação de serviços de implantação e de operação de célula de inteligência competitiva, que visa a vigilância ativa do ambiente tecnológico, comercial, econômico, sociológico, geopolítico, concorrencial, jurídico, regulamentar, normativo, etc. de uma organização. Pela Figura 2, visualizamos o fluxo do processo de IC da Norma AFNOR XP X 50-053:

Partindo-se para as ferramentas em Inteligência Competitiva, Santos (2000), menciona os softwares infométricos ${ }^{6}$, que, para ele, respondem a quatro tipos de necessidades do processo de IC, a saber: a) necessidades de

\footnotetext{
6 Infometria: termo ad otado em 1987 pela Internacional Federation of D ocumentation (IFD) para designar o conjunto de atividades métricas relativas à informação, incluindo também tanto a Bibliometria quanto a Cientometria.
} 
exploração: rapidez e simplicidade; b) necessidades de estruturação: agregação de valor/rentabilização; c) necessidade de posicionamento: detectar indicadores-chave; d) necessidade de pros-pecção: visão de futuro.

Pelo Quadro 4, elaborado por Santos (2000), visualizamos uma síntese das necessidades descritas acima, apresentando os resultados que podem ser obtidos em função dos tipos de tratamento realizados. Duas situações foram consideradas: para informações em formato bibliográfico corpus estruturado, e outra, para análise realizada a partir de textos livres.
Para um caso ou outro, os softwares mais conhecidos, para essas análises, são listados na coluna, à direita.

Além dessas ferramentas para registro das informações necessárias ao controle, dentro da unidade de informação, e sob o enfoque da visão sistêmica da gestão, há que se recorrer a outras ferramentas para o controle da qualidade dos produtos e serviços e das metas a serem atingidas. Referimo-nos em especial à Gestão da Qualidade, Gestão de Recursos Humanos, Marketing, Benchmarking, Reengenharia de Processos.
Da competência de especialista IC

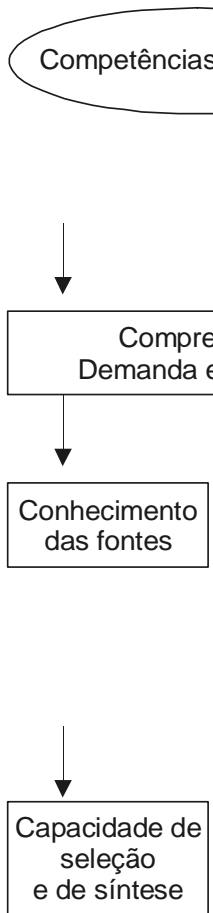

Ferramentas de acesso

Ferramentas de tratamento

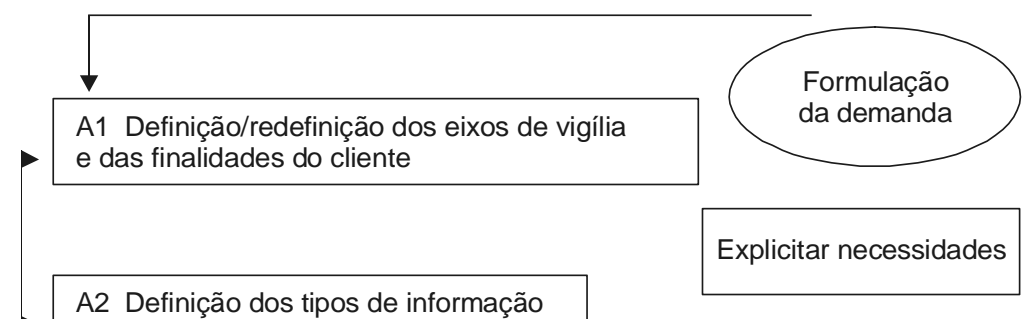
úteis

A3 Identificação e seleção das fontes de informação

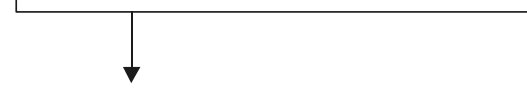

A4 Coleta e seleção das informações

Da expectativa do cliente

A7 - Validação e Ajustes sucessivos
A8 - Comunicaçãodos resultados de vigília
Produto com valor Agregado adaptado

A5 - Análise e organização ao cliente

Figura 2. Fluxo de Processo de IC - Norma AFNOR Xp X 50-053. 
Quadro 4. Resultados obtidos por tipo de tratamento.

\begin{tabular}{|c|c|c|c|}
\hline Necessidades & Tratamentos & Resultados & Software \\
\hline \multicolumn{4}{|c|}{ Análise de Corpus Estruturado } \\
\hline $\begin{array}{l}\text { Exploração } \\
\text { Posicionamento }\end{array}$ & $\begin{array}{l}\text { Contagens simples sobre um } \\
\text { campo }\end{array}$ & $\begin{array}{l}\text { - Autores mais importantes } \\
\text { - Empresas mais importantes } \\
\text { - Publicações mais citadas } \\
\text { - Temas mais importantes }\end{array}$ & $\begin{array}{l}\text { DATAVIEW + (Excel, } \\
\text { Statistic) } \\
\text { TETRALOGIE } \\
\text { DATALIST } \\
\text { TECHNOLOGY }\end{array}$ \\
\hline Estruturação & $\begin{array}{l}\text { Cotejamentos, comparações } \\
\text { entre dois campos ou do campo } \\
\text { com ele mesmo }\end{array}$ & $\begin{array}{l}\text { - Redes de autores (equipe) } \\
\text { - Redes de temas } \\
\text { - Disposições de autores e temas } \\
\text { - Equipes posicionadas por te- } \\
\text { mas-chave }\end{array}$ & WATCH \\
\hline $\begin{array}{l}\text { Estruturação } \\
\text { Prospecção }\end{array}$ & $\begin{array}{l}\text { Cotejamentos, comparações, } \\
\text { de dois campos com um } \\
\text { terceiro. Ex. a data, para } \\
\text { visualizar a evolução notempo }\end{array}$ & $\begin{array}{l}\text { - Estabilidade das equipes } \\
\text { - Emergência de novos temas } \\
\text { - Mobilidade dos autores nos te- } \\
\text { mas } \\
\text { - Mobilidade dos pesquisadores } \\
\text { entre os laboratórios } \\
\text { - Etc. }\end{array}$ & \\
\hline \multicolumn{4}{|c|}{ Análise de Textos Livres } \\
\hline Exploração & Contagens simples & $\begin{array}{l}\text { - Palavras ou expressões mais } \\
\text { importantes }\end{array}$ & $\begin{array}{l}\text { Vários extratores } \\
\text { terminológicos }\end{array}$ \\
\hline Exploração & $\begin{array}{l}\text { Redes de clusters ou } \\
\text { de classes }\end{array}$ & $\begin{array}{l}\text { - Ajuda a navegação (aproxima- } \\
\text { ções sucessivas) }\end{array}$ & $\begin{array}{l}\text { SEMIOMAP } \\
\text { SAMPLER } \\
\text { TEXT NAVIGATOR }\end{array}$ \\
\hline Estruturação & & $\begin{array}{l}\text { - Obsolescência ou emergência } \\
\text { de temas (comparações de } \\
\text { clusters entre períodos de } \\
\text { tempos diferentes) }\end{array}$ & $\begin{array}{l}\text { EVALOG } \\
\text { LEXIMAPPE }\end{array}$ \\
\hline $\begin{array}{l}\text { Exploração } \\
\text { Estruturação } \\
\text { Prospecção }\end{array}$ & $\begin{array}{l}\text { Cartas estratégicas ou } \\
\text { árvores de conhecimento }\end{array}$ & $\begin{array}{l}\text { - Navegação gráfica intuitiva } \\
\text { - Descrição de temas, visualiza- } \\
\text { ção de redes de temas } \\
\text { - Obsolescência ou emergência } \\
\text { de temas, mudanças de posi- } \\
\text { cionamento de um tema sobre a } \\
\text { carta estratégica ou deformação } \\
\text { da árvore em função de novas } \\
\text { informações } \\
\text { - Etc. }\end{array}$ & $\begin{array}{l}\text { SDOC } \\
\text { NEURODOC }\end{array}$ \\
\hline
\end{tabular}

Fonte: Santos (2000, p.213). 


\section{CONSIDERA ÇÕ ES FIN A IS}

Considerando a Gestão da Informação como um aspecto estratégico da economia contemporânea, este artigo se propôs a discutir algumas metodologias empregadas na gestão de processos e serviços informacionais, pelos gestores de Unidades de Informação.

A fundamentação teórica sobre essas metodologias está calcada em nosso conceito de Gestão da Informação como teoria, prática e processo. Principalmente, como prática, como já explicamos na indrodução.

Acreditamos que é importante destacar que, independentemente de trabalharmos com a Gestão da Informação como teoria, prática ou processo, é interessante que tenhamos em mente, com qual nível de informação para a tomada de decisão estamos atuando: se estratégico, tático ou operacional.

A informação é "fluxo" e, por isso, deve perpassar todos os níveis de uma organização, conferindo "poder" a quem sabe compartilhá-la e não cerceá-la, como no passado.

Fluxos de informação, portanto, devem estudar os canais de produção, distribuição e circulação da informação; os processos e suportes informacionais e a apropriação da informação pelas Unidades de Informação, por meio de investigações que tratem: da informação no processo decisório das organizações; a mediação da informação (científica, organizacional, técnica, etc.); as fontes de informação; a gestão de processos e serviços informacionais; a Gestão da Qualidade nas Unidades de Informação; as Tecnologias de Informação; as Redes e os Usuários da Informação (UNIVERSIDADE..., 2003).

Desse modo, explicitar ou objetivar os conteúdos informacionais é missão da área de Gestão da Informação. Recentemente, tivemos a oportunidade de realizar pesquisa de mestrado e resolvemos pesquisar a percepção e a utilização do conceito de gestão da informação, junto aos Gerentes Temáticos de sete cadeias agroalimentares da economia paranaense, do Programa Paraná Agroindustrial. Naquela ocasião em 2001, pudemos constatar os seguintes resultados com relação a essa percepção dos gerentes temáticos do Programa: "Quanto às aplicações da Gestão da Informação, no tocante a metodologias, ferramentas e técnicas de controle informacional, a metodologia mais conhecida é a de "Diagnósticos" (71,4\%); as ferramentas mais utilizadas são de "Estratégia, Liderança e Criatividade" (42,8\%) e as técnicas mais utilizadas são as de "Acompanhamento" $(71,4 \%)$. Vê-se, que, em sua maioria, são técnicas tradicionais da Administração. As surpresas encontradas na pesquisa vão para as cadeias de Aves e Milho, que afirmaram utilizar, respectivamente, de Norma AFNOR XP X 50-053 e softwares infométricos, para monitoração de Inteligência Competitiva. Já a categoria de Coordenação Geral/Assessores mencionou somente utilizar as metodologias de: "Relações Humanas", "Conceituais" e de "Diagnósticos". Desconhece as ferramentas e as técnicas para - trabalho com a Gestão da Informação" (PEREIRA, 2001).

A Gestão da Informação, na percepção desses Gerentes Temáticos e da Coordenação Geral/Assessores, não variou muito entre as cadeias agroalimentares analisadas. A maioria delas, pelas respostas, enquadraria-se num estágio "empírico" de atuação; não tendo alcançado ainda, o estágio da "Gestão Estratégica da Informação", na qual a informação já passaria a ter uma dimensão estratégica. Ou seja, nessa etapa, as cadeias produtivas gerenciariam a informação de forma proativa como fonte de vantagem competitiva, utilizando-se de um processo de planejamento estratégico para a informação de um amplo conjunto de ações (programas, projetos, treinamentos, grupos de melhoria, etc.) para atingir os objetivos de satisfação ótima em todos os elos das cadeias e umas com as outras, e todas com seus 
clientes. Ter visão global dos negócios e trabalhar para a melhoria contínua dos processos envolvidos são as metas da Gestão Estratégica da Informação. Por isso, há necessidade de um conjunto integrado de princípios, metodologias e ferramentas que apóiem a melhoria de produtos, processos e pessoas (PEREIRA, 2001).

Parafraseando Silva e Braga (1999), sobre Gestão de Cadeias Produtivas no Agribusiness:

\section{RE F E R Ê N C I A S}

BRYSON, J. Introducción a la gestión. In: BRYSON, J. Técnicas de gestión para bibliotecas y centros de información. Madrid: Fundación Gérman Sánchez Ruipérez; Madrid: Pirámide, 1992. p.10-31. (Biblioteca del Libro; 51).

BURK, C.; HORTON, F.W. Infomap: a complete guide to discovering corporate information resources. New Jersey: Prentice Hall, 1988. 254p. CIANCONI, R.B. Gerência da informação: mudanças nos perfis profissionais. Ciência da Informação, Brasília, v.20, n.2, p.204-208, 1991.

CRONIN, B. Esquemas conceituais e estratégicos para gerência da informação. Revista da Escola de Biblioteconomia da UFMG, Belo Horizonte, v.19, n.2, p.195-220, 1990.

DAVENPORT, T.H.; PRUSAK, L. Codificação e coordenação do conhecimento. In: DAVENPORT, T.H.; PRUSAK, L. Conhecimento empresarial: como as organizações gerenciam o seu capital intelectual. Rio de Janeiro: Campus, 1998a. 237p.

DAVENPORT, T.H.; PRUSAK, L. Ecologia da informação: por que só a tecnologia não basta para o sucesso na era da informação. São Paulo: Futura, 1998b. 316p.

DENCKER, A.F.M. Métodos e técnicas de pesquisa em turismo. São Paulo: Futura, 1999. 286p.

FUNDAÇÃO COORDENAÇÃO DE APERFEIÇOAMENTO DE PESSOAL DE NÍVEL SUPERIOR (CAPES). Avaliação dos programas de pós-graduação. Documento de Área (Ciência da Informação e Biblioteconomia). Brasília, DF. mai/jun. 1998. Disponível em: <http://www.capes. como é característico das novas áreas do conhecimento, especialmente, daquelas com fortes contornos interdisciplinares, pode-se afirmar que o próprio conceito de Gestão da Informação não tem, ainda, compreensão universalizada na literatura, o que dificulta a disseminação de seus referenciais e ferramentas de trabalho. Daí, a proposição em tê-la, muito modestamente, deste artigo.

gov.br/cursos/autorizados/programasconceitos. htm>. Acesso em: 2 out. 2000.

GESTÃO de unidades de informação: manual/ elaborado pela COLLECTA-Processo, Produto e Coleta de Dados S/C Ltda. Brasília, DF: IBICT, 1997. 259p.

KAST, F.E.; ROSENZWEIG, J.E. The nature of management: modules in management. Chicago, II: Science Research Associates, 1984.

LOJKINE, J. Uma abordagem sistêmica da revolução informacional. In: LOJKINE, J. $A$ revolução informacional. 2.ed. São Paulo: Cortez, 1999. $316 \mathrm{p}$.

LONGO, R.; FRESNEDA, P. Informação como recurso estratégico. In: SANTOS, R.N.M.; LONGO, R.M. Curso MBA Executivo em Administração-Tecnologia de Informação. São Paulo: IBMEC-Business School, 1999. 15 slides em Power Point.

MEGGINSON, L.C.; MOSLEY, D.C.; PIETRI JR., P.H. Fundamentos do controle e administração da informação. In: MEGGINSON, L.C.; MOSLEY, D.C.; PIETRI JR., P.H. Administração: conceitos e aplicações. 4.ed. São Paulo: Harbra, 1998. p.15-494.

MINI-DICIONÁRIO DA LÍNGUA PORTUGUESA. São Paulo: Melhoramentos, 1992. 563p.

PASSOS, C.A.K. Novos modelos de gestão e as informações. In: LASTRES, H.M. M.; ALBAGLI, S. (Org.). Informação e globalização na era do conhecimento. Rio de Janeiro: Campus, 1999. p.58-83, 61-63. 
PEREIRA, J.B. et al. Cenários para a gerência de recursos informacionais no Brasil. Revista da Escola de Biblioteconomia da UFMG, Belo Horizonte, v.19, n.2, p.307-332, 1990.

PEREIRA, E.C. Gestão da informação no agribusiness paranaense: estudo exploratório do Programa Paraná Agroindustrial. 2001. 351f. Dissertação (Mestrado em Planejamento e Administração de Sistemas de Informação) - Curso de Pós-Graduação em Biblioteconomia e Ciência da Informação, Pontifícia Universidade Católica de Campinas, Campinas, 2001.

PINHEIRO, L.V.R. Usuários « informação: o contexto da ciência e da tecnologia. Rio de Janeiro: IBICT, 1982. $66 p$

PONJUÁN DANTE, G. Gestión de información en las organizaciones: principios, conceptos y aplicaciones. Chile: Universidad de Chile, 1998. 222p. (Série Gestión de Información).

PONTES, C.C.C. Administração de sistemas de informação. Campinas: PUC, 1999. Apontamentos de aulas.

RODAS, S.P. Gerência dos recursos informacionais: estudo da situação no Brasil. Rio de Janeiro: UFRJ/IBICT, 1995. 185p.

SANTOS, R.N.M. Métodos e ferramentas para gestão de inteligência e do conhecimento.
Perspectivas em Ciência da Informação, Belo Horizonte, v.5, n.2, p.205-215, 2000.

SANTOS, R.N.M. Gestão do conhecimento. Cuiabá, MT. In: CURSO DE ESPECIALIZAÇÃO DE AGENTES DE INOVAÇÃO E DIFUSÃO TECNOLÓGICA, 17., 2001. 34 transparências.

SILVA, C.A.B.; BRAGA, J.L. Gestão de cadeias produtivas no agribusiness: conceitos básicos e 0 papel da tecnologia da informação. In CONGRESSO BRASILEIRO DE ECONOMIA E SOCIOLOGIA RURAL, 37. Anais... Brasília, DF: Sociedade Brasileira de Economia e Sociologia Rural, 1999. p.105-108.

SVIDÉN, O. Future information systems for road transport: a Delphi panel-derived scenario. Technological Forecasting and Social Change, New York, v.33, n.2, p.159-178, 1988.

TARAPANOFF, K. et al. Técnicas para tomada de decisão nos sistemas de informação. Brasília, DF: Thesaurus, 1995. 163p.

UNIVERSIDADE FEDERAL DE SANTA CATARINA. Mestrado em Ciência da Informação. Linha de pesquisa fluxos de informação. Florianópolis: UFSC, 2003.

VIEIRA, A.S. et al. Demanda por gerentes de recursos informacionais: um estudo preliminar. Revista da Escola de Biblioteconomia da UFMG, Belo Horizonte, v.19, n.2, p.295-306, 1990. 